\title{
$\mathrm{CH}_{4}$ 플라즈마에 따른 $\mathrm{TiN}$ 박막 표면의 식각특성 연구
}

\author{
우종창, 엄두승, 김관하, 김동표, 김창일" \\ 중앙대학교 전자전기공학부
}

\section{The Etch Characteristics of TiN Thin Film Surface in the $\mathrm{CH}_{4}$ Plasma}

\author{
Jong-Chang Woo, Doo-Seung Um, Gwan-Ha Kim, Dong-Pyo Kim, Chang-II Kim* \\ School of Electrical and Electronics Engineering, Chung-Ang University
}

(Received October 1, 2008 ; revised October 27, 2008 ; accepted October 30, 2008)

\begin{abstract}
In this study, we carried out an investigation of the etching characteristics (etch rate, selectivity to $\mathrm{SiO}_{2}$ and $\mathrm{HfO}_{2}$ ) of TiN thin films in the $\mathrm{CH}_{4} / \mathrm{Ar}$ inductively coupled plasma. The maximum etch rate of $274 \AA$ / min for TiN thin films was obtained at $\mathrm{CH}_{4}(80 \%) / \mathrm{Ar}(20 \%)$ gas mixing ratio. At the same time, the etch rate was measured as function of the etching parameters such as RF power, Bias power, and process pressure. The X-ray photoelectron spectroscopy analysis showed an efficient destruction of the oxide bonds by the ion bombardment as well as showed an accumulation of low volatile reaction products on the etched surface. Based on these data, the ion-assisted chemical reaction was proposed as the main etch mechanism for the $\mathrm{CH}_{4}$ containing plasmas.
\end{abstract}

Keywords: Etch, TiN, Inductively Coupled Plasma, surface

\section{1. 서 론}

현재까지 $\mathrm{CMOS}$ 소자의 크기가 $80 \mathrm{~nm}$ 이하로 감 소하면서 짧은 채널효과(short-channel effect)와 같 은 소자의 소형화에 따른 문제점이 점점 심각하게 노출되기 시작하였으며, 종래에 사용되어온 소자구 조 및 제작 기술만으로는 집적도나 소자 동작 특성 개선에 있어 한계에 부딪치게 되었다. 또한 메모리 소자의 트랜지스터의 크기는 메모리 소자의 속도를 향상 시키고, 전력소모를 감소시키기 위하여 급속 히 작아지고 있다. 그러나 메모리 소자 크기의 축 소는 Silicon Oxide에서의 누설 전류의 증가로 인하 여 수반되는 메모리 소자의 열 발생 증가와 게이트 에서의 저 전도성 문제를 발생 시킨다 ${ }^{1-3)}$. 또한 VLSI 용 Packaging와 Silicon Oxide을 비롯한 커패시터의 절연막 두께 역시 엷게 되어 가고 있다. 이렇게 집 적도 증가와 더불어 막의 두께가 얇아짐에 따라 Pin-hole 증가, 불순물 확산과 저항력 감소 문제가

\footnotetext{
*Corresponding author. E-mail : cikim@cau.ac.kr
}

제기되어 이를 보완한 새로운 게이트 절연막이 요 구 되고 있다 ${ }^{4-5)}$. 또한, 실리콘 집적회로기술의 발 전에 따라 지속적인 성능의 개선이 비용의 절감 소 비전력의 감소와 함께 실현되어 왔다. 이러한 실리 콘 반도체 기술의 혁신은 반도체 소자의 특성 즉, 소형화에 따라서 $\mathrm{CMOS}$ 소자의 지속적인 발전을 추구하기 위해 새로운 재료와 기술의 도입이 불가 피 할 것으로 예상된다. 따라서 원자 층 레벨의 조 작을 통한 high- $k$ dielectric, dual metal gate electrode, strained channel 등의 도입이 필요하다. 최근 연구 되고 있는 $\mathrm{TaN}, \mathrm{TiN} \mathrm{WN}$ 등과 같은 금속질화물들 중에, $\mathrm{TiN}$ 은 알루미늄 공정에서 사용되고 연구 되 어온 물질이다. 최근에 high- $k$ 연구가 진행되고 있 는 시점에서 poly-silicon을 대체할 금속전극으로 상 용 될 수 있는 $\mathrm{TiN}$ 의 지속적인 연구가 필요하다. 그 중 단위공정에서의 문제점들에 대한 해결 방안 이 제대로 제시 되어있지 않은 상태이다. 그 단위 공정 중에서도 건식 식각조건에서 일괄공정으로 처 리할 때에 발생할 수 있는 선택비, 상이한 재료에 대한 식각속도의 차이 등의 문제에 대한 연구는 아 
직 이루어지고 있지 못한 설정이담.

따라서 본 연구에서는 $\mathrm{CH}_{4} / \mathrm{Ar}$ 가스를 기반으로 유도결합 플라즈마 (Inductively Coupled Plasma) 시 스템을 이용하여 Metal/high- $k$ gate stack 구조의 금 속배선으로 사용되어질 수 있는 TiN과 마스크로 사 용되어질 수 있는 $\mathrm{SiO}_{2}$ 를 식각하였으며, high- $k$ 물 질의 대표 격인 $\mathrm{HfO}_{2}$ 와의 선택비도 연구 하였다. 가 스 혼합비, $\mathrm{RF}$ 전력, $\mathrm{Bias}$ 전력과 공정 압력에 대 한 식각속도의 변화와 식각 선택비를 관찰 하였고, 빛 방출 분석(Optical Emission Spectroscopy: OES) 을 이용하여 플라즈마 특성과 식각 속도와의 관계 를 분석하였다 ${ }^{2}$. 또한 식각 메커니즘을 더욱 상세하 게 규명하기 위해 XPS(X-ray photoelectron spectroscopy)를 이용하여 TiN 박막과 플라즈마 내 의 라디칼과 식각된 시료 표면의 화학반응 분석을 통해 식각 메커니즘을 고찰하였다.

\section{2. 실험방법}

본 실험에 사용된 기판은 $0.85 \sim 1.15 \Omega \cdot \mathrm{cm}$ 의 비 저항을 갖는 $\mathrm{p}$ 형, 12 인치 실리콘 웨이퍼를 사용하 였다. TiN 박막은 $\mathrm{ALD}$ (atomic layer deposition) 장 비를 이용하여 증착하였다.

이와 같이 준비된 $\mathrm{TiN}$ 박막의 플라즈마 식각은 그림 1에서 보는 유도 결합 플라즈마에서 $\mathrm{CH}_{4} / \mathrm{Ar}$ 가스를 이용하여 식각 실험을 수행하였다. 이때 표 준 공정변수로는 $\mathrm{RF}$ 전력을 $600 \mathrm{~W}, \mathrm{Bias}$ 전력은 $200 \mathrm{~W}$, 공정압력은 $2 \mathrm{~Pa}$, 기판온도는 $30^{\circ} \mathrm{C}$ 로 고정 시켰다. $\mathrm{TiN}$ 의 식각 속도와 $\mathrm{TiN} / \mathrm{SiO}_{2}$ 의 식각 선택 비는 식각 변수인 $\mathrm{CH}_{4} / \mathrm{Ar}$ 가스 혼합비, $\mathrm{RF}$ power, bias power와 공정 압력을 각각 변화시키면서 측정

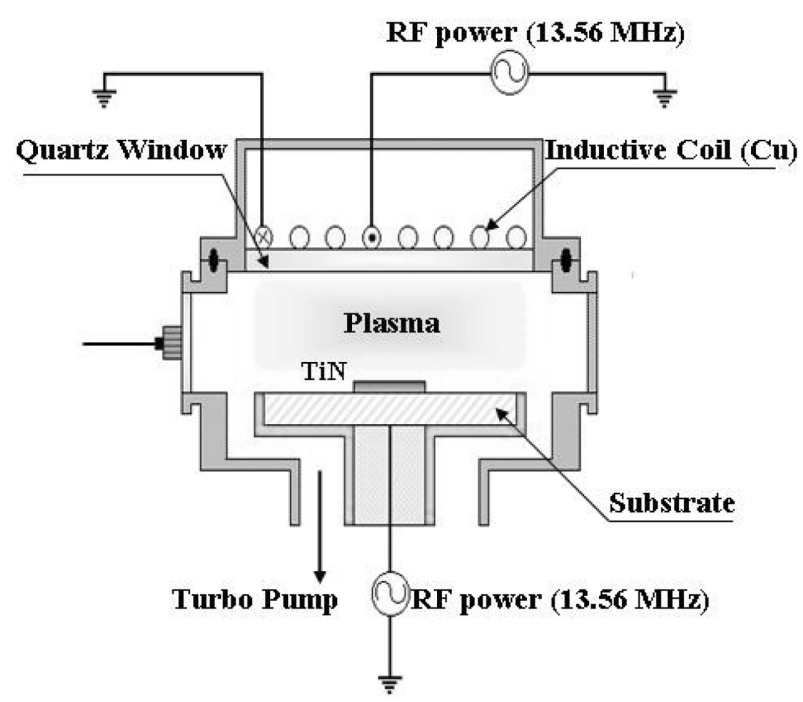

Fig. 1. Schematic of inductively coupled plasma system.

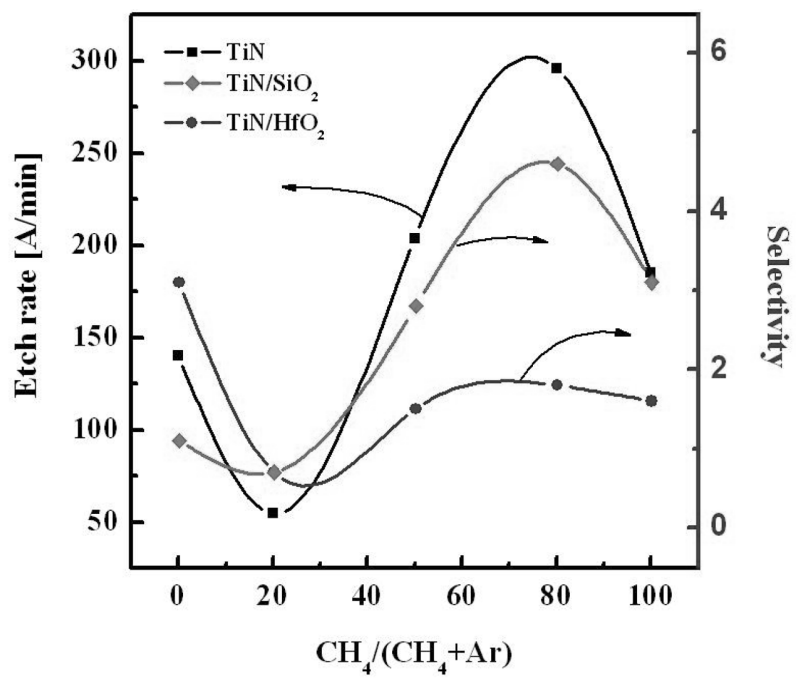

Fig. 2. Etch rate of TiN thin film and selectivities of TiN thin films to $\mathrm{SiO}_{2}$ and $\mathrm{HfO}_{2}$ as a function of $\mathrm{CH}_{4} /$ Ar gas mixing ratio.

하였다. 식각속도는 surface profiler(KLA Tencor, Alpha-step 500)를 사용하여 측정하였으며, $\mathrm{CH}_{4}$ 가 스 첨가 비에 따른 플라즈마에서의 $\mathrm{CH}$ 라디칼과 $\mathrm{Ar}$ 의 상대적 부피 밀도의 변화를 관찰하기 위해 $\mathrm{OES}$ (SC Tech, PCM 402)를 사용하였다. 식각 전후 의 $\mathrm{TiN}$ 박막의 표면 반응을 Thermo VG 사의 SIGMA PROBE XPS 장비를 이용하여 분석하였다. 이 때 XPS 장비는 250 watts의 $\mathrm{Mg} \mathrm{Ka}(1486 \mathrm{eV})$ 를 사용하였다.

\section{3. 결과 및 고찰}

그림 2는 $\mathrm{CH}_{4} / \mathrm{Ar}$ 가스 혼합비에 따른 $\mathrm{TiN}$ 박막 의 식각 속도와 $\mathrm{SiO}_{2}$ 및 $\mathrm{HfO}_{2}$ 대한 $\mathrm{TiN}$ 박막의 선 택비들을 나타내고 있다. 이때의 RF 전력과 Bias 전력은 각각 $600 \mathrm{~W}$ 와 $200 \mathrm{~W}$ 이였으며, 공정 압력과 기판 온도는 $2 \mathrm{~Pa}$ 와 $30^{\circ} \mathrm{C}$ 이다. 그림 2 에 나타난 바 와 같이 $\mathrm{CH}_{4}$ 의 첨가량이 $0 \%$ 에서 $20 \%$ 까지 증가함 에 따라서 식각 속도는 감소하였다가, $\mathrm{CH}_{4}$ 첨가량 이 $20 \%$ 에서 $80 \%$ 까지 증가함에 따라서 $\mathrm{TiN}$ 의 식각 속도는 증가 하게 되어, 최대 식각 속도에 도달하 게 된다. 그리고 $\mathrm{CH}_{4} \quad 100 \%$ 조건에서는 다시 $\mathrm{TiN}$ 의 식각 속도가 감소하게 된다. $\mathrm{CH}_{4}(80 \%) / \mathrm{Ar}(20 \%)$ 의 조건에서 $274 \AA / \mathrm{min}$ 의 최고 식각 속도를 얻었 으며, 이때의 $\mathrm{SiO}_{2}$ 와 $\mathrm{HfO}_{2}$ 대한 선택비들은 각각 $4.64,1.82$ 이었다. $\mathrm{TiN}$ 의 식각 속도가 $\mathrm{Ar}=100 \%$ 조 건 보다 $\mathrm{CH}_{4}=100 \%$ 조건에서 높게 나타나고 있으 며, $\mathrm{CH}_{4}$ 와 $\mathrm{Ar}$ 이 혼합된 플라즈마에서 두 조건보다 높은 식각 속도를 얻을 수 있었다. 이는 $\mathrm{CH}_{4} / \mathrm{Ar}$ 플 라즈마에서의 $\mathrm{TiN}$ 의 식각이 $\mathrm{Ar}$ 이온의 의한 물리 


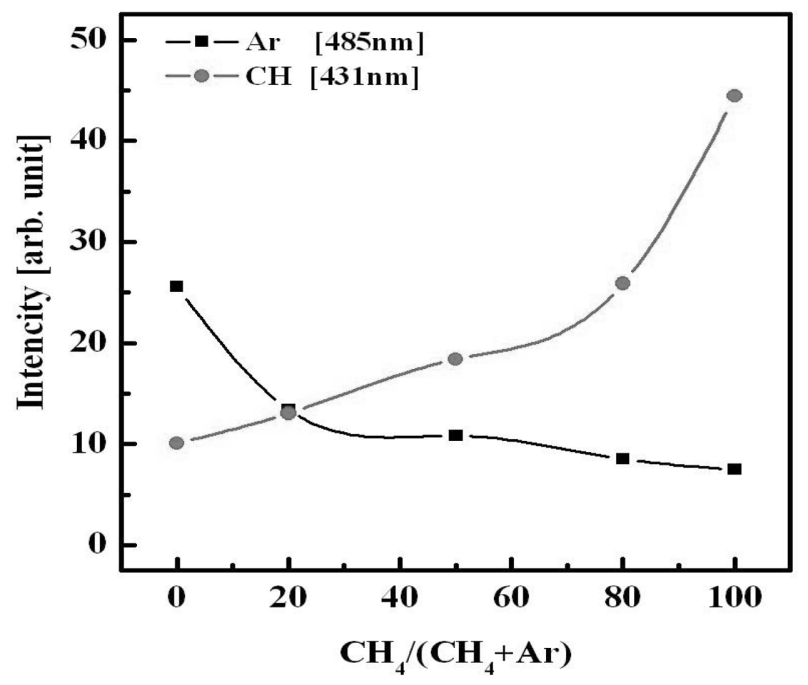

Fig. 3. The optical emission intensity as a function of $\mathrm{CH}_{4} / \mathrm{Ar}$ gas mixing ratio.

적 식각과 $\mathrm{CH}$ 또는 $\mathrm{H}$ 라디칼이 $\mathrm{TiN}$ 과 표면에서 반응하여 형성하는 $\mathrm{TiH}_{2}$ (녹는점: $450^{\circ} \mathrm{C}$ ) 또는 $\mathrm{Ti}_{\mathrm{x}}$ $(\mathrm{CH})_{\mathrm{y}}$ 형성을 통한 화학적 식각의 도움에 의한 것 으로 사료된다. 그림 2에서 $\mathrm{CH}_{4}$ 의 첨가비가 증가 함에 따라서 전자와 여기된 $\mathrm{Ar}$ 이온이 $\mathrm{CH}_{4}$ 기체 분자와 충돌 하여, $\mathrm{CH}$ 라디칼과 $\mathrm{H}$ 와 $\mathrm{C}$ 원자로 해 리되어, $\mathrm{CH}$ 와 $\mathrm{H}$ 의 상대적 부피 밀도가 증할 것으 로 예측된다. 이는 주어진 공정 변수에 대하여 결 정적인 요인이 $\mathrm{H}$ 원자들과 $\mathrm{CH}$ 원자들에 의해 제 공되는 화학적인 식각 반응이라고 사료된다.

그림 3은 $\mathrm{OES}$ 를 이용하여 가스 혼합비에 따른 $\mathrm{CH}_{4} / \mathrm{Ar}$ 플라즈마의 $\mathrm{CH}$ 라디칼 및 $\mathrm{Ar}$ 의 $\mathrm{OES}$ 광 방 출 세기를 측정한 결과이다. $\mathrm{CH}$ 라디칼 및 $\mathrm{Ar}$ 의 상대적 부피 밀도는 각각 $431 \mathrm{~nm}$ 와 $485 \mathrm{~nm}$ 파장의 세기를 비교하여 설명 하고자 한다. 측정된 빛의 세 기가 아래식과 같이

$$
\operatorname{Int} \approx R_{e x}=K_{e x} \times n_{e} \times N
$$

(Int-측정된 광의 세기, $R_{e x}$ - 여기율, $k_{e x}-$ 여기 변 수, $n_{e}$ - 전자밀도와 $\mathrm{N}-$ 입자의 부피 밀도).

이때 $k_{e x} \times n_{e}$ 가 플라즈마 변수의 변화에도 불구하 고 일정하다고 가정 하면, 위의 식 (1)으로부터 비 슷한 파장대에서 측정된 $\mathrm{OES}$ 빛의 세기는 입자들 의 부피 밀도와 직접적으로 비례한다고 할 수 있 다. 그림 3에서 $\mathrm{CH}_{4}$ 혼합비가 증가함에 따라 $\mathrm{Ar}$ intensity가 감소하고 $\mathrm{CH}$ intensity가 증가하는 것을 볼 수 있다. 이는 $\mathrm{CH}_{4}$ 의 혼합비가 증가하면서 $\mathrm{Ar}$ 원자의 상대적인 밀도가 감소함에 따라 나타나는 현상으로 볼 수 있다. $\mathrm{CH}$ 의 증가로부터 $\mathrm{CH}_{4}$ 기체 의 해리과정에서 $\mathrm{H}$ 원자 또한 증가 되었다는 것을 예측 할 수 있다.

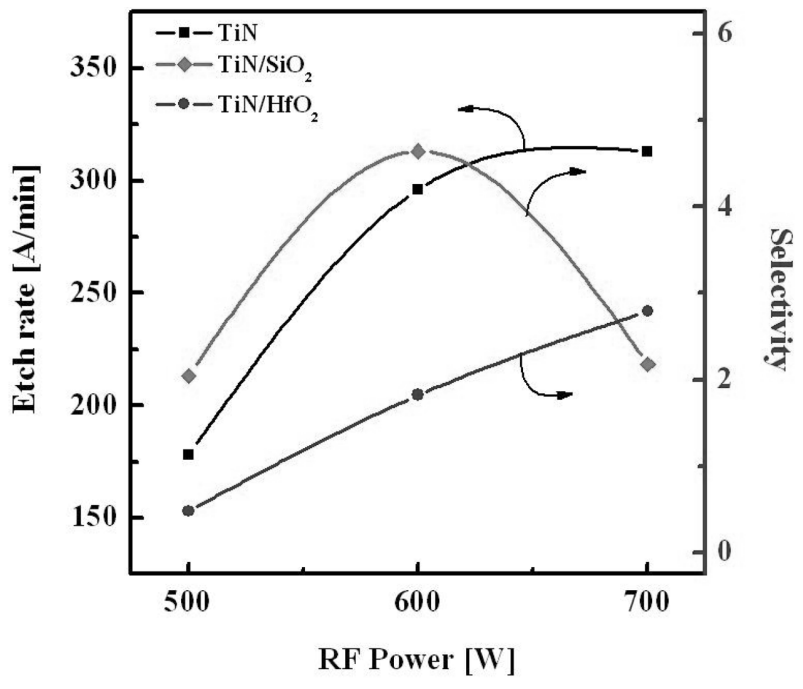

Fig. 4. Etch rate of TiN thin film and selectivities of TiN thin films to $\mathrm{SiO}_{2}$ and $\mathrm{HfO}_{2}$ as a function of RF power.

그림 4에서 나타난 것과 같이, $\mathrm{RF}$ 전력이 증가 할수록 식각 속도는 증가하며, 식각 속도는 $700 \mathrm{~W}$ 일 때 $313 \AA / \mathrm{min}$ 로 가장 높았다. $\mathrm{SiO}_{2}$ 와 $\mathrm{HfO}_{2}$ 에 대한 선택비들은 각각 2.18 와 2.79 이었다. 이것은 $\mathrm{RF}$ 전력이 증가 할수록 $\mathrm{CH}$ 라디칼과 $\mathrm{H}$ 원자 부피 밀도의 증가와 $\mathrm{Ar}$ 이온 유량의 증가로 인하여 물 리적인 식각뿐만 아니라 $\mathrm{CH}$ 라디칼과 $\mathrm{H}$ 원자에 의 한 $\mathrm{TiN}$ 박막 표면과의 활발한 화학적 반응으로 인 해 식각 속도가 증가된 것으로 사료된다. $700 \mathrm{~W}$ 에 서의 $\mathrm{TiN} / \mathrm{SiO}_{2}$ 의 선택비의 감소는 $\mathrm{CH}$ 와 $\mathrm{H}$ 부피 밀 도의 증가에 의하여 $\mathrm{SiO}_{2}$ 의 식각 속도가 휘발성이 높은 $\mathrm{SiH}_{4}$ (녹는점: $\left.-185^{\circ} \mathrm{C}\right)$ 또는 $\left(\mathrm{SiH}_{3}\right)_{2} \mathrm{O}$ (녹는점: $-144^{\circ} \mathrm{C}$ )와 같은 부산물을 형성함으로써 $\mathrm{TiN}$ 의 식 각 속도보다 빠르게 증가하였기 때문으로 판단된다.

그림 5는 $\mathrm{Bias}$ 전력에 따른 $\mathrm{TiN}$ 박막의 식각 속 도와 $\mathrm{SiO}_{2}$ 와 $\mathrm{HfO}_{2}$ 에 대한 선택비들을 나타낸 것이 다. $\mathrm{Bias}$ 전력을 $100 \mathrm{~W}$ 에서 $300 \mathrm{~W}$ 로 변화 시키면 서, $\mathrm{TiN}$ 의 식각 실험을 수행 하였다. 이때, $\mathrm{RF}$ 전 력은 $600 \mathrm{~W}$, 가스 혼합비는 $\mathrm{CH}_{4}(80 \%) / \mathrm{Ar}(20 \%)$, 공 정 압력은 $2 \mathrm{~Pa}$ 과 기판 온도는 $30^{\circ} \mathrm{C}$ 로 고정하였다. 그림 5에서 나타난 것과 같이 $\mathrm{Bias}$ 전력이 증가 할 수록 $\mathrm{TiN}$ 박막의 식각속도는 감소하고, 식각속도는 $100 \mathrm{~W}$ 일 때 $333 \AA / \mathrm{min}$ 로 가장 높았다. Bias 전력 이 증가하면, 기판에 인가되는 바이어스 전압은 증 가하게 되어, 웨이퍼로 향하는 $\mathrm{Ar}$ 이온들의 운동 에너지가 증가하게 되어, 물리적인 스퍼터링 효과 가 증가 하게 된다. $\mathrm{CH}_{4} / \mathrm{Ar}$ 플라즈마를 이용한 $\mathrm{TiN}$ 식각 실험에서는 바이어스 전력이 증가함에 따라서 $\mathrm{Ar}$ 이온의 에너지가 크게 증대되어, 흡착된 $\mathrm{CH}$ 라 디칼과 $\mathrm{H}$ 원자가 표면에 $\mathrm{TiN}$ 과 반응하기 전에 물리 


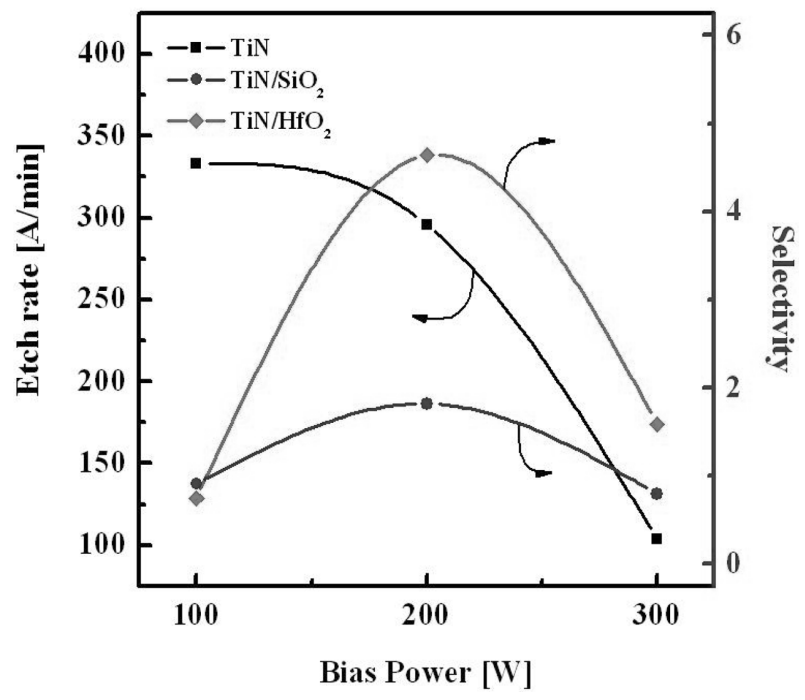

Fig. 5. Etch rate of TiN thin film and selectivities of TiN thin films to $\mathrm{SiO}_{2}$ and $\mathrm{HfO}_{2}$ as a function of Bias power.

적 스퍼터링에 의하여 탈착되기 때문에 식각 속도 가 감소하는 것으로 사료 된닥.

그림 6은 공정 압력에 따른 $\mathrm{TiN}$ 박막의 식각속 도와 $\mathrm{SiO}_{2}$ 와 $\mathrm{HfO}_{2}$ 에 대한 선택비들을 나타낸 것이 다. TiN 박막의 식각속도는 공정 압력이 낮아질수 록 감소하고, 역시 $\mathrm{TiN}$ 박막과 $\mathrm{SiO}_{2}, \mathrm{HfO}_{2}$ 와의 선 택비들도 감소하였다. 일정한 유량이 유입 되는 조 건에서 압력이 감소하게 되면 플라즈마 챔버 내부 에 입자들이 머무르게 되는 잔류시간이 감소하게 된

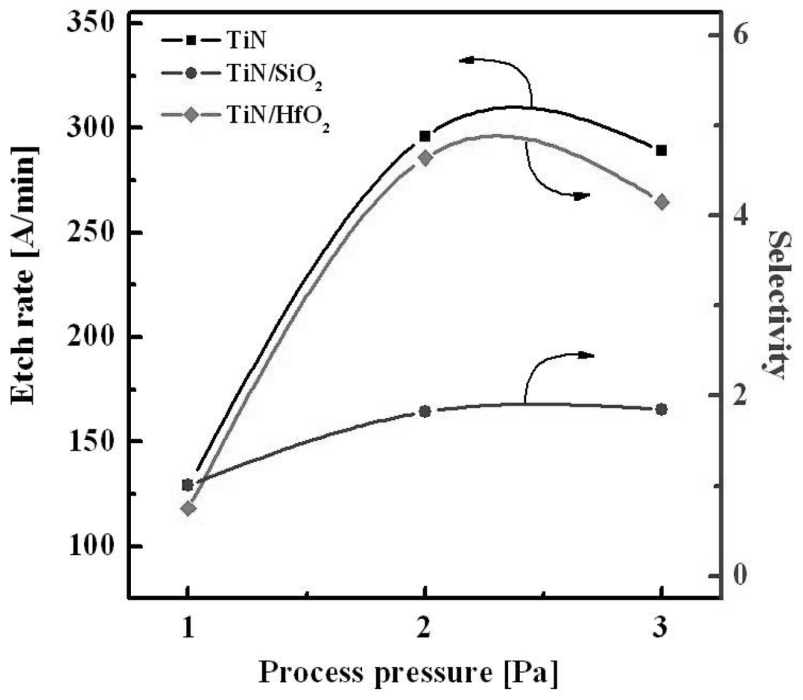

Fig. 6. Etch rate of TiN thin film and selectivities of TiN thin films to $\mathrm{SiO}_{2}$ and $\mathrm{HfO}_{2}$ as a function of process pressure.

다. 즉 충분한 화학반응을 위한 공급되는 $\mathrm{CH}$ 라디 칼과 $\mathrm{H}$ 원자의 부피 밀도가 어느 정도 수준을 유지 하여야 하며, 플라즈마 챔버 내에서 일정 시간 머물 러야 한다. 그러나 압력이 감소함에 따라서 $\mathrm{CH}$ 라 디칼과 $\mathrm{H}$ 원자의 잔류시간이 감소하게 됨으로써 그 결과 $\mathrm{TiN}$ 의 식각 속도가 감소하는 것으로 사료된다.

$\mathrm{TiN}$ 박막 표면에서 라디칼과의 반응에 따른 식각 특성을 이해하기 위해서 XPS narrow scan 분석을 수행하였다. 그림 7 은 $\mathrm{CH}_{4}$ 가스 혼합비에 따라 식
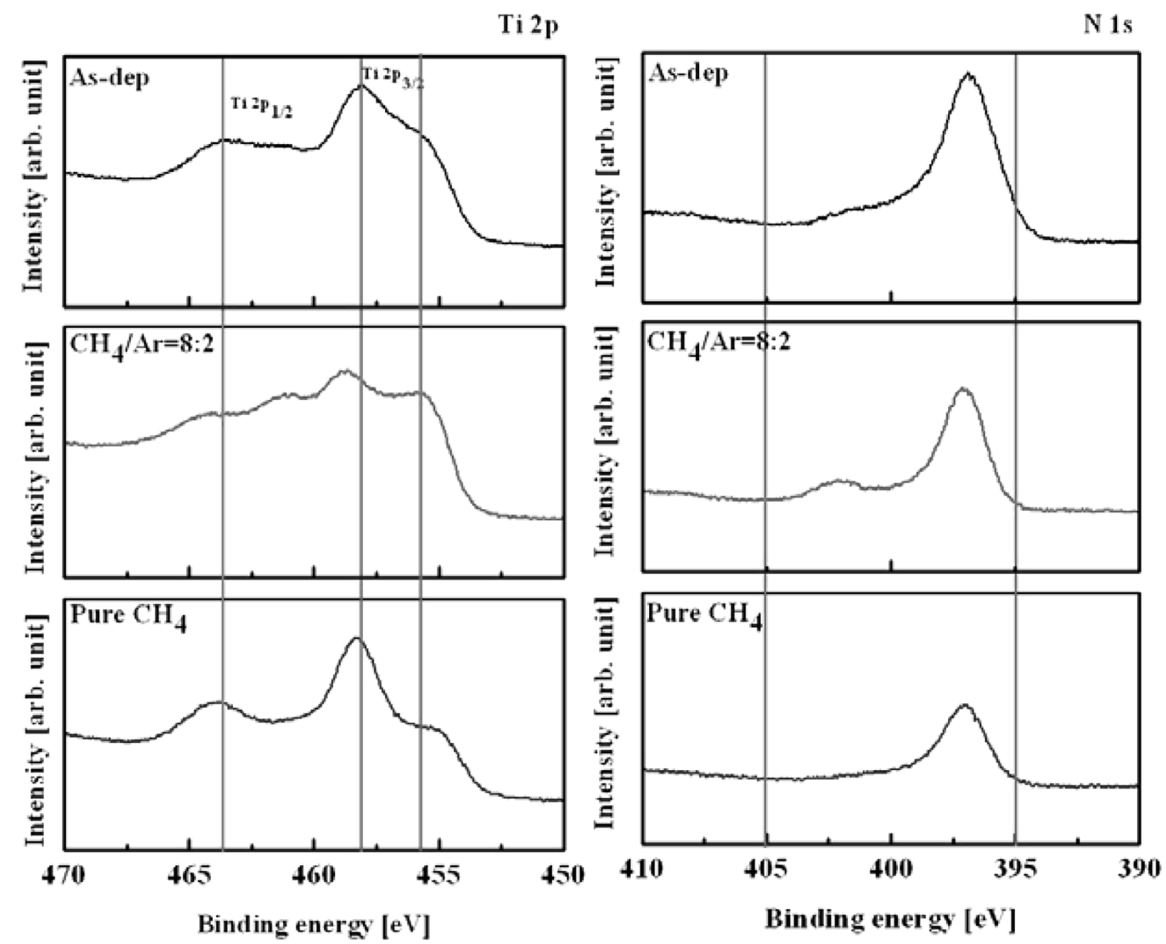

Fig. 7. (a) Ti $2 p$ and (b) $N$ 1s XPS narrow scan spectra of TiN thin film surface etched as a function of $\mathrm{CH}_{4} / \mathrm{Ar}$ gas mixing ratio 
각 한 $\mathrm{TiN}$ 박막 표면에서 XPS의 $\mathrm{Ti} 2 \mathrm{p}$ 와 $\mathrm{N} 1 \mathrm{~s}$ 의 narrow scan 스펙트럼을 나타낸다. $\mathrm{CH}_{4} / \mathrm{Ar}$ 의 가스 혼합비를 변화 시키는 동안 다른 식각 공정 변수는 $600 \mathrm{~W}$ 의 RF 전력, $200 \mathrm{~W}$ 의 바이어스 전력, $2 \mathrm{~Pa}$ 의 공정 압력으로 고정하였다. 그림 7(a)에서 보는 바 와 같이 $\mathrm{CH}_{4}$ 가 첨가된 플라즈마 상태에서 식각한 표면에 대해서만 $\mathrm{Ti} 2 \mathrm{p}_{3 / 2}(458.2 \mathrm{eV})$ 이 높은 에너지 쪽으로 이동하는 것을 볼 수 있다. 이는 $\mathrm{CH}$ 라디 칼의 높은 유속으로 인하여 $\mathrm{TiN}$ 표면에서 화학적 인 작용이 가장 활발히 일어났을 뿐만 아니라 반응 생성물에 대한 가장 낮은 이온의 도움 탈착속도(ionassisted desorption rate)를 보인 것으로 볼 수 있다. 즉, $\mathrm{CH}_{4}$ 가스의 농도를 증가시킬수록 반응 생성물 에 의해서 식각된 표면의 식각 부산물이 증가 된다 는 것이다. 그림 7(b)은 $\mathrm{TiN}$ 박막의 식각 전후의 $\mathrm{N}$ $1 \mathrm{~s}$ 스펙트럼이다. $\mathrm{N} \mathrm{1s}$ 스펙트럼에서 $396.9 \mathrm{eV}$ 와 $402.2 \mathrm{eV}$ 의 결합에너지를 가지는 2 가지의 중첩되는 피크가 나타남을 볼 수 있다. 이것은 첫째 $\mathrm{N}-\mathrm{Ti}$ 결 합에 관련된 것으로 판단할 수 있다. 이것은 $\mathrm{Ar}^{+}$이 온의 충격으로 인해 $\mathrm{TiN}$ 격자구조에서 더 많은 자 유 질소가 생성되기 때문으로 판단된다. 하지만 $\mathrm{CH}_{4}$ 가스가 포함된 플라즈마 상태에서는 두 경우의 피 크가 모두 감소함을 볼 수 있다. 이는 $\mathrm{Ar}$ 가스에 $\mathrm{CH}_{4}$ 를 첨가함으로 인해 $\mathrm{Ti}$ 와 $\mathrm{CH}$ 라디칼과의 화학 적인 반응으로 인해 더 빠르게 깊게 질화물 결합을 깰 뿐만 아니라, $\mathrm{NH}$ 결합, $\mathrm{TiH}_{2}$ 결합과 $\mathrm{Ti}(\mathrm{CH})_{\mathrm{x}}$ 결 합 형성을 통하여 $\mathrm{TiN}$ 의 식각이 증가된다는 것을 알 수 있다 ${ }^{8,9}$.

\section{4. 결 론}

본 논문에서는 $\mathrm{CH}_{4} / \mathrm{Ar}$ 플라즈마를 이용한 $\mathrm{TiN}$ 박 막의 식각에서 $\mathrm{CH}_{4}$ 가스의 농도가 증가될수록 그 리고 RF 전력과 공정 압력이 증가할수록 $\mathrm{TiN}$ 박막 의 식각 속도가 증가하였다. $\mathrm{CH}_{4}(80 \%) / \mathrm{Ar}(20 \%)$ 조 건에서 $\mathrm{TiN}$ 의 최대 식각속도는 $296 \AA / \mathrm{min}$ 이었으며 $\mathrm{SiO}_{2}$ 와 $\mathrm{HfO}_{2}$ 에 대한 식각 선택비들은 각각 4.64와
1.82 이었다. $\mathrm{CH}_{4} / \mathrm{Ar}$ 플라즈마 상태에서 $\mathrm{TiN}$ 박막의 식각은 $\mathrm{Ar}$ 이온의 물리적인 스퍼터링에 의해 Ti-N 결합이 끊어지고 $\mathrm{CH}, \mathrm{H}$ 라디칼에 의한 시료 표면 에서의 화학 반응에 의해 식각이 된다. 또한 라디 칼과 시료와의 반응으로 인한 비휘발성의 식각 부 산물을 $\mathrm{Ar}$ 이온의 스퍼터링에 의해서 시료 표면에 서 효과적으로 탈착 시킬 때 식각 반응은 활발히 일어나게 되어 식각속도의 증가가 야기 되었다.

\section{감사의 글}

본 연구는 (주하이닉스반도체에서 시행하는 "산 학 - 연구지원 사업”에 의해 수행되었으며 이에 감 사드립니다.

\section{참고문헌}

1. A. Le Gouil, O. Joubert, G. Cunge, T. Chevolleau, L. Vallier, J. Vac. Sci. Tech. B, 25(3) (2007) 767-778.

2. G. H. Kim, K. T. Kim, J. C. Woo, C. I. Kim, Ferroelectrics, 357(1) (2007) 41-47.

3. W. T. Chang, T. E. Hsieh, C. J. Lee, J. Vac. Sci. Technol. B, 25 (2007) 1265-1269.

4. S. M. Sze, VLSI Technology, New York, McGrawHill Book Company (1983) 106.

5. R. H. Dennard, F. H. Gaensslen, H. N. Yu, N. Rideout, E. Bessous, and A. R. Leblanc, IEEE J. Solid State Circuits., SC-9 (1974) 256.

6. W. S. Hwang, J. H. Chen, W. J. Yoo, V. Bliznetsov, J. Vac. Sci. Technol. A, 23(4) (2005) 964-970.

7. K. B. Jung, H. Cho, Y. B. Hahn, D. C. Hays, E. S. Lambers, Y. D. Park, T. Feng, J. R. Childress, S. J. Pearton, J. Vac. Sci. Technol. A, 17(4) (1999) 2223-2227.

8. D. R. Lide, "Handbook of Chemistry", CRC Press, 2004 10(3)-10(15).

9. B. Y. Jeong, M. S. Hwang, C. M. Lee, and M. H. Kim, J. Kor. Inst. Met \& Mater., 38(6) (2000) 823-828. 